\title{
Formation of Innovative Strategies of Regional Economic Development
}

\author{
Sergey A. Tronin, ${ }^{+*}$ Tatiana A. Rodermel, ${ }^{\ddagger}$ Milana G. Uspaeva, ${ }^{\beta}$ Anna V. Shashkova, ${ }^{i}$ and Mauricio \\ Calesci $^{i}$
}

\section{Abstract}

The new contours of innovative development of economic systems associated with the appearance of network models of innovation and new types of innovation: social, sustainable, user and inclusive, differ from the traditional approach to the functioning of the raw material model of the economy. The role and place of innovation infrastructure of economic systems in the development of national innovation systems remain paramount. In this research, the essence of the definition of "innovation infrastructure" in relation to economic systems is supplemented and expanded. In doing so, it specifies the factors providing the formation of the infrastructure of innovative activity of the economic systems which have an impact on the innovativeness of elements of economic systems at the micro-, meso- and macro level. The subject-object structure of information infrastructure of innovative activity of economic systems including business environment, innovative environment, information environment and communication environment is proposed. In addition, it also proposes the model of development of infrastructure of innovative activity focused on technological innovations on the basis of implementation of technological platforms. The worked-out model of development of technological infrastructure of innovative activity of the economic system (macro level) contains the directions of transformation of the meso- and micro level where a special role is assigned to the creation of free economic zones which contribute to the development of new forms of interaction of the R\&D sector with the real sector of the economy, which will increase the susceptibility of the economic system of Russia and society as a whole to innovation and lead to the development of technological entrepreneurship and the formation of an innovative economy of a new type.

Keywords: Development, Innovation, Structure, Enterprise, Economy, Russia

\footnotetext{
${ }^{+}$Department of Corporate Finance and Corporate Governance; Financial University under the Government of the Russian Federation, 125993, 49 Leningradskiy Ave., Moscow, Russian Federation

${ }^{*}$ Corresponding Author, Email: Tron1977@rambler.ru

¥ Department of Clinical Psychology; Surgut State University, 628403, 1 Lenina Ave., Surgut, Russian Federation

${ }^{\beta}$ Department of Finance and Credit, Chechen State University, 366007, Boulevard Dudayev, Grozny, Russian Federation

i Department of Constitutional Law, Moscow State Institute of International Relations (MGIMO), 119454, 76 Vernadsky Ave, Moscow, Russian Federation

'Department of World Economics; Universidad de Buenos Aires, Av. Córdoba 2122, 1113 Caba Ciudad de Buenos Aires, Argentina

(C) 2019 Tronin et al. This is an Open Access article distributed under the terms of the Creative Commons Attribution License (http://creativecommons.org/licenses/by/2.0), which permits unrestricted use, distribution, and reproduction in any medium, provided the original work is properly cited.
} 


\section{Introduction}

At the present stage, the Government of the Russian Federation is taking active measures to form a domestic model of the innovation infrastructure of the economic system. New types of technoparks, high-tech zones, major development institutions, are being created. Nevertheless, the current state of innovation infrastructure does not yet allow the country to achieve its objectives fully. Thus, for the period up to 2020, Russia should enter the 5 top countries in terms of Gross Domestic Product (Purchasing Power Parity). The achievement of this goal means the appearance of a qualitatively new image of the future of Russia by the end of the next decade by increasing the efficiency of the innovation infrastructure of the domestic economic system (Friedmann, 1982; Hägerstrand, 1967; Silagadze, 2017; Silagadze, 2018). Thus, the speed of implementation of innovative reforms in the economic system and the possibility of implementing an innovation process will depend on the level of development of innovation infrastructure (Van et al., 2017).

The actuality of this research is due to the need for the formation and development of the infrastructure of innovative activity of the domestic economic system, the scientificallybased solution to the problems of its current state and the development of effective mechanisms for improving the infrastructure of innovative activity (Jansen, 2002).

The experience of developed countries suggests that every developed country builds its own innovative spiral which is a continuous sequence of "research" - "production" cycles which over and over again, at every new turn of the spiral leads to the increase of performance and quality of products and services. The innovation spiral is the main driving force of economic development (Shcherbakov, 2017; Shekhovtsev, 2000). The practical implementation of new products and technology is possible with improved management decision-making mechanisms and improved production processes that, in turn, stimulate the development and use of new products and technology (Pencheva et al., 2018).
The generation and promotion of innovation create the conditions for the creation of the environment in which innovative technology appear, are introduced and spread (Shikhov, 2009; Shitz, 2004; Ushakov et al., 2017a). The effectiveness of innovation can be measured by the net profit that remains with the enterprise after the payment of mandatory payments and taxes (Jungblut, 2016).

The goals to increase profits can be achieved by improving the quality of goods and services, diversifying production, increasing the technical level of production, reducing taxes commensurate with the cost of research and development as well as the use of accelerated depreciation. Innovative development of the economic system implies the presence of innovative potential, which consists of resources and conditions (Chang, 2012). In our opinion, the innovative potential is a set of scientific, financial, human and intellectual resources used for innovation. Indeed, innovation potential is determined by qualified personnel and institutional conditions. If scientific and technical development and invention are new products, then innovation is a new benefit since it pursues the goal of obtaining a new benefit (Xavier, 2012: 420).

Innovation as an economic category is based on four structural elements:

- an institutional economic regime that encourages the effective use of existing and new knowledge needs to be emphasised as "enabling" as it relates to incentives;

- educated, creative, qualified personnel and human resources in general;

- infrastructure;

- innovative system.

The degree of infrastructure development affects the efficiency of the national production system. Taking into account the theoretical and methodological statements about the essence of the concept of "innovative development", we interpret this concept as a set of interrelated 
and interdependent structural elements (institutional regime, human resources, infrastructure and innovative system) that contribute to the competitiveness of the national economy and are the most important factors of sustainable economic development. Innovation is one of the critical criteria of product quality that determines involving high costs to achieve it (Porter, 2002; Porter, 2001). Innovation as an achievement should be studied together with the innovative process.

Organising innovation involves the following components:

- subjects of innovation (association of people who jointly implement the development, implementation and production of innovation);

- a set of processes and actions aimed at performing the necessary functions in innovation (forms, methods and processes that are carried out in innovation);

- structures to improve the relations between innovation elements and subsystems.

To date, the innovative activity includes consulting the companies whose task is to organise innovative activities by attracting highly qualified specialists in the field of scientific knowledge. In a broad sense, innovation is the procedures and means by which scientific discoveries are implemented in socio-economic innovation (Shekhovtsev, 2000: 26).

An innovative approach is a systematic process of qualitative changes in products, means of labour, objects of labour, technology, as well as production and management organising (Schumpeter, 1982). This process aims to improve the competitiveness and efficiency of production. Scientific and technical renewal, production and technological applicability and investment attractiveness to a certain extent refer to the criteria of innovation. Innovation reflects criteria for evaluating the degree of novelty, needs of market participants both in demand and supply and indicators which characterise the level of efficiency of innovative products.

The sources of innovation are different by nature and type (Yakovets, 2004; Yakovets, 2002). The first type, defined as "science-technologyinnovation", is based on the production and application of systematic scientific and technical knowledge. The second type is the result of the "create - use - interact" chain; that is, it is based on know-how arising in informal learning and experimentation processes. The source of innovation of the first type is systematic knowledge, while the basis of innovation of the second type is implicit (non-verbal) knowledge arising from the practical experience of individuals.

For a detailed studying of the problem, we undertook the following tasks:

- to study the particularities of innovative infrastructure;

- to reveal the factors that affect the development of economic systems;

- to study the main directions of national policy in different countries;

- reveal and analyse the elements of the infrastructure of knowledge.

This research begins with a description of the materials and methods deployed. Following this, we critically discuss the results of the research.

\section{Materials and Methods}

The primary source of this knowledge is the research laboratories of large industrial companies. Such kind of innovation culminates in the development of new knowledge with global applications. The identification of different types of knowledge is associated with the idea of innovation as an interactive process in which industrial companies interact with both research organisations and suppliers and consumers (Shashkova, 2018).

Systematic knowledge, taken separately, does not provide any economic benefits. It is complementary knowledge (explicit and implicit) that plays the most crucial role. However, as noted in different studies (Shitz, 2014), there is a 
point of view that unites innovative processes, especially in science-intensive industries. This is demonstrated at the level of public policy in setting goals, focusing on such instruments as tax incentives, training in bio- and nanotechnology and strengthening the links between firms and universities in these areas.

The innovation of the second type is underestimated, including international comparisons of the innovative development level. In comparison, it is customary to use such traditional criteria as the number of patents, citation and venture capital activity (Dotdueva et al., 2016). Close interaction with external consumers and product users and services is a prerequisite for the implementation of numerous product innovation. Such kind of innovation characterises such indicators as the presence of interdisciplinary working groups, quality circles, systems of collection and accounting of proposals, interaction in the work of functional units and cooperation with consumers. However, these indicators are not yet used anywhere to evaluate the level of innovative activity (Kolesnikov et al., 2018; Sharafutdinov et al., 2018).

Innovation is not always the result of scientific research. The ideas that lead to innovation find further expression in the course of extensive contact and interaction with suppliers, customers and even competitors, and it is not because of real scientific knowledge. Besides, the knowledge required for innovation is different from the knowledge obtained in the process of scientific inquiry. It is necessary to distinguish between the tasks of the development of scientific research and innovation.

\section{Results and Discussion}

The availability of appropriate infrastructure is essential for the development of innovation. In the economic literature, there is a sufficient number of definitions of innovation infrastructure (Freeman, 1990: 10). Organisations need common physical infrastructure (roads, electricity, water, and healthcare). At the same time, they require a particular infrastructure, such as:
- providing infrastructure (incentive investment payments, the attraction of venture companies and scientific and technical information centres of technology transfer);

- cooperation infrastructure (state research institutes, universities and engineering units).

Infrastructure, as part of the national innovation system, occupies a special place. Its most significant subcomponent is innovation infrastructure which can be represented in the form of organisations such as technology centres, institutions (industry or functional), and soft organisations: innovation centres and similar bridge organisations (Lundvall, 2011). Solid elements include physical (industrial zones, technology parks, science parks and innovative centres) and technological infrastructure that is presented with the latest technology and tools of the organisation (for example, research and testing centres, Academy of scientific institutions, development centres and laboratories).

Innovative development of economic systems depends on the factors of sectoral and intersectoral specialisation of the organisation, the system of mechanisms of state regulation and the possibility of using market mechanisms, and the predominance of certain types of organisations. Innovative development is an innovative process that includes the development of a system of factors and conditions necessary for its implementation (Asheim, 2002: 80). In recent years, external factors which affect the innovative development of the Russian economy have significantly changed. The factors that limit innovative development are divided into two groups: objective and subjective. Objective factors include:

- the imperfection of the mechanism of economic turnover of intellectual property;

- weak legislative-legal framework for innovation (Abikenov et al., 2019);

- system of insurance of innovative risks; 
- underdeveloped

innovation infrastructure and venture capital;

- physical and moral deterioration of the technological and research base.

Among the subjective factors, there are noted lack of incentives for innovation, low level of innovative competencies, reproduction of models of outdated technology applying and established management methods. The factors that contribute to the innovative development in the near future are ones relevant to the world level of scientific and technical potential that is able to implement the necessary organisational, economic and financial conditions, available methods of technological development, qualified engineering and technical personnel that is sufficient in composition and structure, etc. The factors that hinder innovative development include ineffective regulatory and legal regulation of innovation. The stimulation of innovation is one of the main directions of state policy in developed countries. The principal directions of the economic system development policy are (Lundvall, 2011) formation of an integrated system of economic, organisational, financial and legal factors as well as conditions for the development of innovation.

A systematic approach to the analysis of the external environment allows creating a multivariate path of development. The effectiveness of the economic system is affected by a number of external (exogenous) and internal (endogenous) factors of innovative development. Exogenous factors create general conditions for the innovative organisation functioning in the form of opportunities: be free to innovate; freely trade goods, services, patents and technology with foreign and local partners; participate in international cooperation. Endogenous (internal) factors are consumption and investment. In the process of experience and analytic data accumulation, it has been revealed that models of endogenous growth contribute to economic development in the long run, because they take into account technological progress and admit the important role of the state policy in economy development.
The impact of these factors on the innovative activity of organisations forms a set of mechanisms inherent in the economic system. Mechanisms specific to the economic system can be divided into two groups: laid down in the system of state regulation of the economy and based on the unregulated interaction of supply and demand. The mechanisms can be combined in the form of organisations that regulate the innovative process and stimulate innovation activity, the presence of standard and special forms of economic relations between different market participants about the exchange of goods and services, obtaining loans, the possibility of using the potential of world markets, etc. (Yankovsky, 2006: 22). Primary factors can provide the innovative development of the economic system. The most critical factors in modern conditions are such as modern infrastructure, highly qualified and educated personnel and scientific potential (Lundvall, 2011). Among the factors which hinder the development of innovative infrastructure are:

- underdeveloped mechanisms for lending innovation at the initial stage of the life cycle;

- underdevelopment of public-private partnership;

- barriers to taxation (Ushakov et al., 2017b);

- insufficient development of marketing activities to form a system of market research and forecasting (Kireev et al., 2016; Buley et al., 2017);

- weak innovative activity;

- problems of venture investment;

- problems of coordination of investment activities and programmes.

Along with the well-known principles of infrastructure, we consider it necessary to supplement the principles of innovative infrastructure with such points as innovative interaction, balanced development of innovation infrastructure subsystems and ensuring the innovation infrastructure functioning. The most important principle 
should be considered the establishment of relations between organisations and their environment with the use of business models, the result of which is precisely innovative interaction. The principle of innovative interaction involves the creation and promotion of joint innovative products and technology based on the company's interaction with its external environment, that is, suppliers, consumers, competitors, innovative intermediaries, etc.

Thus, the term "innovation" in different literary sources is understood in different ways which are determined by differences in economic entities that use innovation, the diversity of innovation, the level of development of the economy as a whole and other factors.

In our opinion, innovation is the result of innovative activities of individuals and legal entities, brought to the stage of commercial use as well as obtained recognition of the market and distributed in it in the form of a new product, service, technology, process or organisational solution. The country is taking measures to increase innovation. New elements have appeared in the innovative system, new types of universities have been opened, and new clusters have been announced (Ushakov et al., 2017c). The dynamics of industrial activity in the field of innovation has improved to some extent. Nevertheless, it can not be said that innovation has become widespread. The measures implemented so far do not lead to the expected results (Nonaka, 2000: 19). The demand-driven innovation generated by technical and production experience is underestimated, which is demonstrated in the imbalance of innovative policy; the leading role of enterprises as the main subject of any innovative system is overlooked.

The availability of appropriate infrastructure is essential for the development of innovation. In developed countries, there is an increase in new types of innovation. This is, in particular, service, user and social innovation that require network communities and development of various partnerships and new functions of innovative infrastructure. Objective necessity and environmental factors determine the innovative development of organisations. In this regard, the critical task of innovative infrastructure in organisations is to ensure maximum adaptation of all systems, business processes and resources to the rapidly changing environment. Information infrastructure of innovation is an extensive network of organisations that provides access to scientific and technical information. This can include regional information networks and the Internet. The information technology park is an exclusive economic zone with a preferential tax and customs regime for all information and telecommunication companies which operate there. Financial infrastructure provides innovative enterprises with access to financial resources. Not particularly common is the system of financing the innovative business angels-private investors.

The sales component is an actual direction of the innovative activity infrastructure, as it contributes to the promotion of knowledgeintensive products of organisations in the domestic and global markets. Knowledge infrastructure consists of technology, organisational culture and organisational structure:

- technology as an element of knowledge infrastructure capabilities includes information technology that integrates existing knowledge into the organisation, create, store and transfer new knowledge in the enterprise;

- organisational culture is seen as a critical factor in building and strengthening knowledge management in the organisation that affects how employees acquire and share knowledge;

- the organisational structure is a set of structural units united by a degree of hierarchy, rules, functions of control and subordination.

Knowledge infrastructure provides conditions and creates prerequisites for effective development of a knowledge management system in the enterprise. Technology, organisational culture and organisational structure are interrelated elements for the 
systematic placement, creation and use of knowledge at all organisational levels of the enterprise. The capabilities of the knowledge process include acquiring, transforming, applying, and protecting the knowledge that is necessary for taking advantage of infrastructure capabilities:

- knowledge acquisition is the company's activities aimed at identifying and acquiring the knowledge required by the organisation for sustainable development in the future and are an integral part of current operations;

- at the stage of knowledge transformation, all information and acquired knowledge from different sources of the internal and external environment are transformed into organisational knowledge and become part of the company;

- knowledge applying is the use of knowledge at the right time, that is when certain knowledge can have the most beneficial impact on the activities of the enterprise;

- knowledge protection is an organisation's activity aimed at protecting organisational knowledge through patents, copyrights and information technology. An organisation can create an internal protection system through limited access to organisational knowledge. Protection of knowledge is a crucial part of keeping them inside the organisation because the flow of knowledge can critically affect the results of operations, the company's position in the market and conditions of competition.

Knowledge infrastructure includes a subsystem of knowledge infrastructure, which includes:

- network interaction of business education subjects within the framework of public-private partnership;

- access to information about the system of business education, the results of monitoring the activities of educational institutions

- work on the integration of science and industry;

- development of the business education system.

Thus, knowledge management covers most aspects of the organisation's activities, and knowledge itself is the primary source of achieving a competitive advantage. To date, the number of new forms of innovative infrastructure can be attributed to the innovative camps shared by FAB-labs (structure 3D-printing) as well as co-working space which can be provided by public and private actors. Information and communication technology plays a particularly important role in the development of new types of innovation. The transition to a digital economy intensifies the diffusion of innovation. Innovation infrastructure can be defined by its elements: industrial-technological, informational, financial, marketable, knowledge infrastructure, consulting and personnel.

Technological infrastructure (technology parks, innovation and technology centres, and special economic zones (SEZ)). The main objects of innovative infrastructure - technoparks - are service and production bases for the creation and introduction of innovations within which innovators can receive a complex of specialised services. Technoparks have a small number of enterprises with advanced technology, carrying out orders for the creation and development, the production of modern equipment and devices, but the technoparks themselves are not involved in the innovation financing. According to experts, a characteristic feature of the created technoparks and business incubators is the narrowing their activities to the lease of production and administrative areas and various equipment. World powers are developing new programmes of innovative development; there is a need to create specialised websites of a new generation. The basis of this process can be technological platforms. The technological infrastructure includes: 
- facilities (corporate campuses, technological parks, technopoles and science labs);

- financial and investment structures including venture capital companies;

- the infrastructure of services and competencies which aim in the provision of IT services and IT products;

- educational and research structures represented by universities, research institutions and university business incubator or Park;

- information systems for communication and data exchange.

We have identified the factors that ensure the formation and development of technological platforms:

- institutional environment adequate to the required directions of economic transformation;

- level of human capital development;

- condition of the production unit;

- level of development of production infrastructure;

- level of financial support of technological processes;

- scientific and technical potential;

- potential for international cooperation.

Such kind of local infrastructure of technology promotion as industrial one has become widespread in the world. As a kind of local infrastructure-less known as industrial districts (industrial districts of Italy). In this country, most manufacturing small and medium-sized enterprises operate within a kind of territorialorganisational complexes, called industrial districts. A special class of local infrastructure includes innovative regional systems. They also include incubators, research parks and fibreoptic lines.

Soft infrastructure (or knowledge infrastructure) includes educational establishments, universities and other connecting organisations that ensure horizontal and vertical knowledge transfer between individual organisations and companies, as well as know-how, patents, and utility models. The innovative regional system consists of the following main components: companies, additional and supporting companies, environment and infrastructure. The first component includes companies that introduce innovation to the market, register patients and conduct financial resources for research, development and innovation. The second component is companies that provide additional and support services for the first component: knowledge providers, subsuppliers, institutions for cooperation, etc.

The infrastructure can be divided into three separate parts:

1) institutions that create the environment:

- institutions that form the legal basis for the development of entrepreneurship, strategic documents to support the creation and development of innovation in companies as well as innovative entrepreneurship in general;

- companies that provide business facilitation; organisations formed to support the creation of industrial clusters and business networks;

- institutions that form conventions, traditions and customs in the field of business ethics. These institutions support the so-called social capital;

2) multiple initiatives:

- public initiatives that support the creation of finance and the development of innovative entrepreneurship and innovative infrastructure of all types;

- private initiatives that provide financial support for the ideas of entrepreneurs without sufficient fixed capital-business angels. These institutions support venture capital;

3) solid and soft infrastructure: 
- physical infrastructure (innovative centres, industrial areas, science parks, technology parks, etc.);

- technological infrastructure represented by the latest equipment and tools in the centres (testing centres, research institutes, Academy of scientific institutions and research laboratories);

- knowledge infrastructure provided by educational institutions, universities, colleges and other organisations that facilitate horizontal or vertical knowledge transfer among individual organisations and companies.

The overall innovative infrastructure, according to some authors (Yakovets, 2002; Vinichenko et al., 2017), includes:

- the general policy of the country in the field of science and technology;

- mechanisms to support basic research and higher education;

- resource commitments which support innovation;

- the overall level of human and financial resources allocated to innovation as well as the cumulative stock of technological knowledge, generation and commercialisation of new ideas.

\section{Conclusion}

The national knowledge base consists of investment in basic research, cumulative innovation and overall technological complexity. It is necessary to distinguish between the concept of "innovation infrastructure" and "infrastructure of innovation". Innovation infrastructure includes sub-components such as:

- traditional basic infrastructure which includes organisations that perform soft (example patent offices) and hard (example new measurement technologies on which new product standards will be based) functions. This subcomponent also includes the Bureau of standards, statistical offices, scientific museums, research centres;

- the innovative (technological) infrastructure itself, contains basic and advanced components, soft and hard elements;

- development unit of innovative policy.

The overall innovative infrastructure consists of several elements highlighted by NIS perspectives and innovative growth theory. Sokolov refers to innovative policy to the key elements of innovative infrastructure. According to the scientist, the innovative policy is a set of subsidy programmes and grants, R\&D taxation policy, education and financing policy, intellectual property protection policy, the policy of openness to international trade and investment. Innovative resources include labour force in the field of science and engineering, access to higher and postgraduate education, access to risk capital and information infrastructure of high quality.

\section{References}

Abikenov, A., Idrysheva, S.K., Zharbolova, A.Z., Apakhayev, N., Buribayev, Y.A., \& Khamzina, Z.A. (2019). The problems of effectiveness and implementation of the international legal norms of the states of the Eurasian Economic Union (EAEU). Bulletin of the Georgian National Academy of Sciences, 13(1), 175-181.

Asheim, B.T. (2002). Regional Innovation Systems: The Integration of Local 'Sticky' and Global 'Ubiquitous' Knowledge. Journal of Technology Transfer, 27(1), 77-86.

Buley, N.V., Demchenko, T.S., Bondaletov, V.V., Bondaletova, N.F., \& Makushkin, S.A. (2017). Management policy promotion as element of complex of commercial organizations marketing. International Journal of Applied Business and Economic Research, 15(12), 307-316.

Chang, C.-M. (2012). Factors Affecting Knowledge Management Success: the Fit Perspective. Journal of Knowledge Management, 16(6), 847-861.

Dotdueva, Z.S., Gorlov, S.M., Marchenko, E.V., Takhumova, O.V., Kaverzin, S.A., \& Sugaipova, 
I.V. (2016). The methodology for the formation of the regional food-producing clusters. International Review of Management and Marketing, 6(6), 27-31

Freeman, C. (1990). The Economics of Innovation. England: ESDU

Friedmann, J. (1982). World City Formation: An Agenda for Research and Action. International Journal of Urban and Regional Research, 6, 309344.

Hägerstrand, T. (1967). Innovation diffusion as a spatial process. Chicago: University of Chicago Press.

Jansen, F. (2002). Era of Innovation. Moscow: Infra-M.

Jungblut, J. (2016). From Preferences to Policies in Coalition Governments - Unpacking PolicyMaking in European Higher Education. Public Policy and Administration, 32(4), 323-348.

Kireev, V.S., Nekrasova, M.L., Shevchenko, E.V., Alpatskaya, I.E., Makushkin, S.A., \& Povorina, E.V. (2016). Marketing management as the realization process of research, production and sale activity of the enterprise. International Review of Management and Marketing, 6(6), 228-234.

Kolesnikov, Yu.A., Pavlyuk, A.V., Radachinsky, Yu.N., \& Rodionova, N.D. (2018). Problems of implementation of public-private partnership in Russia. European Research Studies Journal, 21, 187-197.

Lundvall, B.-A. (2011). Innovation Systems and Economic Development, 9na. Conferencia Internacional Globelic. Retrieved from http://www.globelics.org/wpcontent/uploads/2016/05/GWP 2012-01.pdf.

Nonaka, I. (2000). SECl and Leadership: a Unified Model of Dynamic Knowledge Creation. Long Range Planning, 33/1, 5-34.

Pencheva, I., Esteve, M., \& Mikhaylov, S.J. (2018, 12 June). Big Data and Al - A Transformational Shift for Government: So, What is Next for Research? Public Policy and Administration. Retrieved 20 March 2019 from, https://journals.sagepub.com/doi/full/10.1177/ 0952076718780537

Porter, M. (2002). Contention. Moscow: Williams.

Porter, M. (2001). The Competitive Advantage on Nations. New York: Palgrave.

Schumpeter, J. (1982). Theory of Economic Development. Moscow: Progress.

Shashkova, A.V. (2018). Corporations and the State: Emerging of the Problem of Corporate Liability. Opción, 34(Special Issue 14), 432-458.

Shcherbakov, V.S. (2017). Iteration as a Regulatory Function of Education Management. Eurasian Journal of Analytical Chemistry, 12(7b), 1211-1219.

Shekhovtsev, A. (2000). Free Economic Zones: World Experience and Development Prospects in Russia. Economic Issues, 10, 23-33.

Shikhov, A.V. (2009). Information Technology. Service Sales of Finished Products. Dairy Industry, 3, 42-44.

Shitz, M. (2004). In the Union of Education and Science born Russian Nevtony and Plato. Russian Newspaper. Retrieved 15 March 2019 from,http://informika.ru/text/magaz/newpaper /messedu/2004/cour0403/3500.htm.

Silagadze, A. (2017). History of Georgian economic thought: Relation between the center and the region. Bulletin of the Georgian National Academy of Sciences, 11(4), 138-144.

Silagadze, A. (2018). Some aspects of economic ideas in Shota Rustaveli's "the knight in the panther skin". Bulletin of the Georgian National Academy of Sciences, 12(1), 161-167.

Ushakov, D., Akhmetova, S.G., \& Nevskaya, L.V. (2017a). Economic growth and environmental performance: Correlation issues and future priorities. International Journal of Ecological Economics and Statistics, 38(4), 164-172.

Ushakov, D., Bandurin, V., Bandurin, A. (2017b). Taxation regime as a factor of mutually intergrated macroeconomic systems' dynamics. Montenegrin Journal of Economics, 13(1), 171179. 
Ushakov, D., Elokhova, I., \& Kozonogova, E. inspection. Eurasian Journal of Analytical (2017c). Post industrialization prospects in the dynamics of socioeconomic transformations: Cluster approach. International Journal of Ecological Economics and Statistics, 38(2), 23-32.

Van, H.T., Huu, A.T., \& Ushakov, D. (2017). Liberal reforms and economic growth: Current issues and interrelations. Journal of International Studies, 10(4), 109-118.

Vinichenko, M.V., Karácsony, P., Demcheko, T.S., llina, I.Y., \& Makuchkin, S.A. (2017). Improvement of youth personnel policy: Social

Chemistry, 12(7): 1069-1077.

Xavier, S.-I-M. (2012). The Global Competitiveness Report. Geneva.

Yakovets, U.V. (2002). The Strategy of Scientific and Innovative Breakthrough. Economist, 5, 311.

Yakovets, U.V. (2004). Epochal Innovation of the XXI century. Moscow: Economy.

Yankovsky, K.P. (2006). Organisation of Investment and Innovation. St. Petersburg: Peter. 